\title{
Chronic respiratory symptoms in children and adults living along streets with high traffic density
}

\author{
Arie Oosterlee, Marjon Drijver, Erik Lebret, Bert Brunekreef
}

\begin{abstract}
Objectives-To investigate if the population living along streets with high traffic density has a higher prevalence of chronic respiratory symptoms.

Methods-A sample of 673 adults and 106 children (0-15 years), living along busy traffic streets in the city of Haarlem was compared with a control sample of 812 adults and 185 children living along quiet streets. Exposed and control streets were selected on the basis of model calculations of $\mathrm{NO}_{2}$ concentrations. A postal questionnaire containing questions about respiratory symptoms and several potential confounders was used to collect information from the study subjects.

Results-After adjustment for potential confounders, children living along busy streets were found to have a higher prevalence of most respiratory symptoms than children living along quiet streets. Adjusted odds ratios were significant for wheeze and for respiratory medication used. Risk ratios were higher for girls than for boys, with significant adjusted odds ratios between $2 \cdot 9$ and $15 \cdot 8$ for girls. In adults, only mild dyspnoea was more often reported by subjects living along streets with high traffic density.

Conclusions-The results suggest that living along busy streets increases the risk of developing chronic respiratory symptoms in children.
\end{abstract}

Community Health Service, Haarlem, The Netherlands

A Oosterlee

M Drijver

Department of

Chronic Disease and

Environmental

Epidemiology,

National Institute of

Public Health and

Environmental

Protection, Bilthoven,

The Netherlands

E Lebret

Department of

Epidemiology and

Public Health,

University of

Wageningen,

Wageningen, The

Netherlands

B Brunekreef

Correspondence to:

Dr Arie Oosterlee,

Dr Arie Oosterlee,

Community Health Service,

PO Box 206,

The Netherlands.

Accepted 1 December 1995
In this paper, we present the results of a cross sectional survey by questionnaire on chronic respiratory symptoms in children and adults living along busy traffic streets in the town of Haarlem and surrounding communities in The Netherlands. The survey was part of a larger, exploratory questionnaire survey of families living along busy streets, about a broad range of health indicators, living conditions, and demographic variables. The main hypothesis at the start of the investigation was that people living along busy streets would have demographic characteristics different from other citizens who had different lifestyles and thus differences in health.

\section{Methods}

POPULATION

The study took place in the city of Haarlem and surrounding communities, an urban region with about 220000 residents. For selection of busy traffic streets, environmental traffic maps have been used. These are city maps displaying estimated noise and air pollution levels of each traffic street in the region. Air pollution levels are estimated with a mathematical model (calculation of air pollution by road traffic (CAR) model). ${ }^{6}$ In this model, predicted levels of air pollution are calculated for a certain distance from the axis of the road. For each street, parameters are used such as the kind of vehicles passing (cars, buses, trucks, petrol powered, diesel powered, etc), mean traffic density, emission rates of exhaust gases for a specific type of engine, local topography such as presence and type of buildings along the road, city background concentrations, and regional variations in meteorological conditions. Formulae for the CAR model are derived from a recently developed, more complex street dispersion model, which is partly based on wind tunnel experiments and partly on actual measurements (including $\mathrm{NO}_{2}$ ) from the existing national air quality monitoring network of regional, city, and street monitoring stations. Internal validation of the CAR model showed satisfactory results. External validation was limited to a comparison with measurements in 10 streets in one city in the Netherlands, giving a mean (SD) error of $6 \%$ $(9 \%)$ for $\mathrm{NO}_{2}$ peak concentrations. The model is calibrated yearly with the latest data about the relevant input parameters. A more detailed description of the CAR model is given elsewhere. ${ }^{6}$

One of the advantages of the environmental traffic maps and the CAR model is that factors determining the dispersion of exhaust gases such as the presence of "street canyons" are taken into account as well, instead of only traf- 
fic density to categorise streets. So, for the purpose of this study, streets were selected which are relatively narrow, have relatively high traffic density and which are therefore characterised by relatively high levels of air pollution.

At the time of the study, environmental traffic maps of Haarlem and surrounding communities were available of carbon monoxide (CO) and nitrogen dioxide $\left(\mathrm{NO}_{2}\right)$. Of these two, the traffic maps of $\mathrm{NO}_{2}$ were chosen: the traffic maps of $\mathrm{CO}$ showed only a few streets with high concentrations of $\mathrm{CO}$ and were not suitable for the study. Selected classes of $\mathrm{NO}_{2}$ concentrations were from $116 \mu \mathrm{g} / \mathrm{m}^{3}$ (62 ppb) to $150 \mu \mathrm{g} / \mathrm{m}^{3}$ (80 ppb) (98th percentiles of 1 hour mean concentrations of $\mathrm{NO}_{2}$ ), calculated for the pavement nearest to the axis of the streets. These categories correspond with an estimated traffic density of 10000 to 30000 vehicles every 24 hours.

All addresses at the selected streets were listed. Some of the addresses with large front gardens were excluded.

To obtain a control population, for each whole or part of a busy street, a street with little traffic was chosen in the same neighbourhood. If possible, streets were chosen with the same type of housing or buildings as in the busy street. About the same numbers of addresses were selected from the two street categories.

Name, birth date, sex, and marital state of each occupant of the selected addresses were obtained from the different municipal population registries. A random sample was taken from the selected addresses. For Haarlem, the sampling fraction was $0 \cdot 4$. Slight oversampling was used for the other communities, for a better comparison of the different communities in the statistical analyses. Questionnaires were posted to all occupants of homes in the sample in February 1991.

\section{QUESTIONNAIRES}

For children up to 16 years of age a questionnaire was used, to be completed by the parents. The questionnaires contained questions derived from the World Health Organisation, the British MRC, and the American Thoracic Society questionnaires. ${ }^{7}$ Questions were included about chronic cough, episodes of cough with phleghm, wheeze, dyspnoea, attacks of dyspnoea with wheeze, and doctors' diagnosis of asthma. Additional questions were asked about medication, allergy, frequency of contact with the family doctor, and frequency of absenteeism from school. For adults, questions about chronic cough, dyspnoea, wheeze, and diagnosis of asthma were derived from a questionnaire commonly used in the Netherlands, ${ }^{8}$ and completed with questions on medication and allergy.

Adults and parents of children were asked to write down separately which type of medication for respiratory or asthmatic problems were used. Upon receiving the questionnaires the answers were checked and categorised by one of the authors (current use of specific medication for asthma, or respiratory prob- lems in general: occasional use of medicines for lungs or airways).

Several potential confounding variables were asked for as well-for example, lifestyle factors, living circumstances, housing conditions (such as type of heating and ventilation), and habits.

An accompanying letter explained the aim as being a general study on the influence of housing and living conditions on health. No special reference to air pollution by road traffic was made.

Parents were asked to complete a questionnaire for each of their children. The parents and other adults could return the questionnaires by freepost. In a period of seven weeks, three successive reminders were sent to the non-responders.

\section{STATISTICAL ANALYSIS}

The data from each child's questionnaire were linked to the data of the male parent. In the absence of a father, the data from the child's mother was used. Exploratory data analysis included univariate and stratified analyses to produce counts and percentages and to assess the amount of heterogeneity between strata and of possible modification of effects (Woolf's test for multiplicative interaction ${ }^{9}$ ). Calculation of Mantel-Haenszel adjusted odds ratios (ORs) was used to assess the extent of confounding by specific covariates. The statistical software Epi Info was used. ${ }^{10}$

Logistic regression analyses were applied to calculate results simultaneously adjusted for confounding variables. ${ }^{11}$ Firstly, all covariates of potential confounders known already from scientific literature were entered simultaneously. ${ }^{11}{ }^{12}$ If in a stratified analysis any of these covariates was shown to cause heterogeneity between strata, interaction terms were tested for inclusion in the model with stepwise procedures. Age was included as a continuous variable; the results were compared with models with three age categories. Other possible confounders or proxy indicators of confounding (family characteristics or housing conditions), which in stratified analyses caused a $10 \%$ or larger change in the ORs, ${ }^{13}$ were tried for their possible contribution to the model as well. If inclusion caused a change in the adjusted OR of $10 \%$ or more, these covariates were included in the final model. ${ }^{12}$ No attempts were made to improve the precision of estimates by deleting variables from the model. ${ }^{11}$ An exception was made only when inclusion of variables resulted in instability of the model. ${ }^{14}$ Logistic regression analyses were performed with the statistical software SPSS/PC ${ }^{+} .{ }^{15}$

Standard algorithms were used for calculation of $95 \%$ confidence intervals ( $95 \% \mathrm{CIs}$ ), so no correction was made for the finite sampling fraction or for the design effect of the cluster sampling procedure. In separate analyses, this design effect was estimated with equations described by Kalton ${ }^{16}$ and Levy and Lemeshow. ${ }^{17}$ The loss in precision caused by the cluster sampling seemed to more or less balance the effect on precision caused by the high finite sampling fraction. 
Table 1 Characteristics of study population, children 0-15 years old

\begin{tabular}{|c|c|c|c|}
\hline & $\begin{array}{l}\text { Total } \\
n(\%)\end{array}$ & $\begin{array}{l}\text { Study } \\
n(\%)\end{array}$ & $\begin{array}{l}\text { Controls } \\
n(\%)\end{array}$ \\
\hline $\begin{array}{l}\text { Numbers (\%) } \\
\text { Age of child (y): }\end{array}$ & $291(100)$ & $106(36)$ & $185(64)$ \\
\hline $\begin{array}{l}\text { Age or crua }(y): \text { : } \\
0-10 \\
11-15\end{array}$ & $\begin{array}{r}122(42) \\
89(31) \\
80(28)\end{array}$ & $\begin{array}{l}49(46) \\
29(27) \\
28(26)\end{array}$ & $\begin{array}{l}73(40) \\
60(32) \\
52(28)\end{array}$ \\
\hline $\begin{array}{l}\text { Sex of child: } \\
\text { Boys } \\
\text { Girls }\end{array}$ & $\begin{array}{l}135(47) \\
155(53)\end{array}$ & $\begin{array}{l}54(51) \\
51(49)\end{array}$ & $\begin{array}{r}81(44) \\
104(56)\end{array}$ \\
\hline $\begin{array}{l}\text { Duration of residency } \\
\text { (estimate, y): } \\
0-4 \\
5-9 \\
10-15\end{array}$ & $\begin{array}{r}141(49) \\
83(29) \\
65(23)\end{array}$ & $\begin{array}{l}54(51) \\
26(25) \\
26(25)\end{array}$ & $\begin{array}{l}87(48) \\
57(31) \\
39(21)\end{array}$ \\
\hline $\begin{array}{l}\text { Number of parents in family: } \\
\text { Single parent } \\
\text { Two parents }\end{array}$ & $\begin{array}{r}32(11) \\
255(89)\end{array}$ & $\begin{array}{l}16(16) \\
87(85)\end{array}$ & $\begin{array}{r}16(9)^{\star} \\
168(91)\end{array}$ \\
\hline
\end{tabular}

$\star \mathrm{P}<0 \cdot 10$. groups were similar for age and sex. More than half of the children had lived at their current address for the last five years or more.

Most of the parents were married, in the study population less than in the control population $(75 \% v 84 \%, P<0.05)$. In $16 \%$ of households in the study population, only one parent was present, in the control population this percentage was $9 \%(P=0.08)$. Table 1 shows these descriptive data.

The mean duration of parents living at the present address in the study population was $2 \cdot 4$ years longer than in the control population $(P$ $=0.03)$. Of children in the study population $72 \%$ were born at the present address (correlation between living duration and age $r=0.78, \mathrm{P}<0.001)$. In the control population this was $66 \%(r=0.79, \mathrm{P}<0.001)$. In the study population, parents with children with one or more chronic respiratory symptoms had lived at their home address for a mean of 2.6 years less than parents with children without symptoms $(P=0.3)$. The study and control populations showed no significant differences between age, occupation, education, working situation, nationality, or type of health insurance of the parents.

The study population seemed to live somewhat more frequently in apartment buildings, with more houses rented from a private owner, and with a higher mean rent.

Parents in the study population significantly less often reported the presence of moulds or of signs of moisture and in general less often had an impression of high humidity inside their homes. No other major differences were found in housing conditions, including passive smoking, presence of pet animals, type of cooking or heating appliances, or presence of an unvented gas heater (data not shown).

Table 2 shows the prevalences of respiratory

Table 2 Numbers, prevalences, and results of logistic regression analyses (numbers, crude and adjusted ORs, and 95\% CIs of adjusted ORs) of symptoms of asthma and other respiratory disease in children 0-15 years old

\begin{tabular}{|c|c|c|c|c|c|c|c|}
\hline Symptom or item & $\operatorname{Subjects}_{n}^{*}$ & $\begin{array}{l}\text { Study } \\
\text { population } \\
n(\%)\end{array}$ & $\begin{array}{l}\text { Control } \\
\text { population } \\
n(\%)\end{array}$ & $\begin{array}{l}\text { Subjects in } \\
\text { logistic } \\
\text { regression† } \\
n\end{array}$ & $\begin{array}{l}\text { Crude } \\
\text { OR‡ }\end{array}$ & $\begin{array}{l}\text { Adjus } \\
\text { OR }\end{array}$ & $\begin{array}{l}\text { ted } \\
(95 \% C I)\end{array}$ \\
\hline $\begin{array}{l}\text { Chronic cough } \\
\text { Periods of cough with pleghm } \\
\text { Wheeze-ever } \\
\text { Wheeze-in past year } \\
\text { Dyspnoea-ever } \\
\text { Dyspnoea-in past year } \\
\text { Attacks of dyspnoea }\end{array}$ & $\begin{array}{l}290 \\
288 \\
291 \\
291 \\
286 \\
286\end{array}$ & $\begin{array}{l}3(2 \cdot 9) \\
2(1 \cdot 9) \\
27(25 \cdot 5) \\
18(16 \cdot 9) \\
8(7 \cdot 7) \\
6(5 \cdot 7)\end{array}$ & $\begin{array}{l}2(1 \cdot 1) \\
4(2 \cdot 2) \\
21(11 \cdot 4) \\
13(7 \cdot 0) \\
10(5 \cdot 5) \\
9(4 \cdot 9)\end{array}$ & $\begin{array}{l}247 \\
248 \\
249 \\
249 \\
244 \\
244\end{array}$ & $\begin{array}{l}2 \cdot 5 \\
0 \cdot 8 \\
1 \cdot 9 \\
1 \cdot 6 \\
0 \cdot 8 \\
0 \cdot 7\end{array}$ & $\begin{array}{l}-5 \\
-5 \\
2 \cdot 1 \\
1 \cdot 5 \\
0 \cdot 7 \\
0 \cdot 7\end{array}$ & $\begin{array}{l}- \\
\overline{(0 \cdot 99-4 \cdot 4)} \\
(0 \cdot 6-3 \cdot 7) \\
(0 \cdot 2-2 \cdot 3) \\
(0 \cdot 2-2 \cdot 4)\end{array}$ \\
\hline with wheeze-ever & 289 & $18(17 \cdot 1)$ & $14(7 \cdot 6)$ & 248 & $1 \cdot 7$ & $2 \cdot 0$ & $(0 \cdot 8-4 \cdot 7)$ \\
\hline with wheeze-in past year & 288 & $10(9 \cdot 5)$ & $7(3 \cdot 8)$ & 247 & $1 \cdot 7$ & $2 \cdot 1$ & $(0 \cdot 6-6 \cdot 8)$ \\
\hline $\begin{array}{l}\text { (past year) } \\
\text { Doctor's diagnosis of asthma }\end{array}$ & 286 & $21(20 \cdot 1)$ & $17(9 \cdot 3)$ & 245 & 1.5 & 1.6 & $(0 \cdot 7-3 \cdot 7)$ \\
\hline $\begin{array}{l}\text { Respiratory medication-ever } \\
\text { Asthma medication-currently } \\
\text { Doctor's diagnosis of allergy }\end{array}$ & $\begin{array}{l}289 \\
287 \\
279\end{array}$ & $\begin{array}{c}5(4 \cdot 8) \\
28(26 \cdot 7) \\
7(3 \cdot 0)\end{array}$ & $\begin{array}{c}2(1 \cdot 1) \\
24(13 \cdot 2) \\
3(1 \cdot 7)\end{array}$ & $\begin{array}{l}248 \\
245 \\
237\end{array}$ & $\begin{array}{l}2 \cdot 5 \\
2 \cdot 3 \\
2 \cdot 8\end{array}$ & $\begin{array}{l}-1 \\
2 \cdot 2 \\
4 \cdot 8\end{array}$ & $\begin{array}{l}\overline{(1 \cdot 1-4 \cdot 6)} \\
(0 \cdot 9-27 \cdot 5)\end{array}$ \\
\hline $\begin{array}{l}\text { ever } \\
\text { Frequency of ear pain }\end{array}$ & 286 & $16(15 \cdot 2)$ & $19(10 \cdot 5)$ & 245 & 1.4 & 1.4 & $(0 \cdot 6-3 \cdot 4)$ \\
\hline $\begin{array}{l}\text { (annual mean) } \\
\text { Contact with family doctor }\end{array}$ & 221 & $0 \cdot 30$ & 0.34 & - & - & - & - \\
\hline $\begin{array}{l}\text { (any contact past } 3 \text { months) } \\
\text { School absenteeism }\end{array}$ & 291 & $41(38 \cdot 7)$ & $69(37 \cdot 3)$ & - & 一 & - & - \\
\hline $\begin{array}{l}\text { (any 1-week period in the } \\
\text { past year) }\end{array}$ & 278 & $23(23 \cdot 7)$ & $37(20 \cdot 4)$ & - & - & - & - \\
\hline
\end{tabular}

Logistic regression with simultaneous adjustment for age, sex, education of the mother, passive smoking, presence of an unvented geyser, type of heating appliance, home humidity, presence of pet animals, and crowding.

unvented geyser, type of heating appliance, home humidity, presence of pet animals,
${ }^{*}$ Crude number of subjects with answers about respiratory disease characteristics.

${ }^{\star}$ Crude number of subjects with answers about respiratory disease characte

† Number of subjects with complete data for logistic regression analyses.

ҒCrude ORs calculated over the same number of cases as adjusted ORs. John Wiley 1989; 126-33). 
Table 3 Logistic regression: adjusted ORs and 95\% CIs of children 0-15 years old: boys and girls separately

\begin{tabular}{llc}
\hline Symptom or item & $\begin{array}{l}\text { Adjusted OR } \\
\text { boys }(95 \% \text { CI })\end{array}$ & $\begin{array}{l}\text { Adjusted OR } \\
\text { girls }(95 \% \text { CI) }\end{array}$ \\
\hline Wheeze-ever & $1 \cdot 2(0 \cdot 4-3 \cdot 7)$ & $4 \cdot 4(1 \cdot 4-13 \cdot 6)$ \\
$\begin{array}{l}\text { Wheeze-in past year } \\
\text { Attacks of dyspnoea with wheeze }\end{array}$ & $0 \cdot 7(0 \cdot 2-2 \cdot 5)$ & $5 \cdot 3(1 \cdot 1-25 \cdot 0)$ \\
$\quad$ ever & $0 \cdot 9(0 \cdot 2-3 \cdot 2)$ & $4 \cdot 8(1 \cdot 3-17 \cdot 7)$ \\
Attacks of dyspnoea with wheeze & $0 \cdot 4(0 \cdot 1-2 \cdot 6)$ & $15 \cdot 8(1 \cdot 4-174 \cdot 4)$ \\
$\quad$ in past year & $1 \cdot 3(0 \cdot 4-4 \cdot 4)$ & $2 \cdot 2(0 \cdot 7-7 \cdot 5)$ \\
One or more symptoms (past year) & $1 \cdot 7(0 \cdot 6-5 \cdot 1)$ & $2 \cdot 9(1 \cdot 1-7 \cdot 9)$ \\
Respiratory medication & $1 \cdot 1(0 \cdot 3-4 \cdot 0)$ & $2 \cdot 5(0 \cdot 7-9 \cdot 2)$ \\
Doctor's diagnosis of allergy &
\end{tabular}

Logistic regression with simultaneous adjustment for age, education of the mother, passiv smoking, presence of an unvented geyser, type of heating appliance, home humidity, presence of pet animals, and crowding.

Results were calculated with $109-112$ boys and 135-137 girls.

Not in this table are chronic cough, periods of cough with phlegm, dyspnoea, diagnosis of asthma, and asthma medication. Those results were not reliable for one or both groups of boys and girls because of numerical problems (Hosmer DW, Lemeshow S. Applied logistic regression. New York: John Wiley 1989; 126-33).

symptoms that were reported for the children. The prevalence of symptoms in the control population varied between $1.1 \%$ for chronic cough and $11.4 \%$ for ever wheezing. In the study population, the prevalence was higher for most of the symptoms, varying between $1.9 \%$ for periods of cough with phlegm and $25.5 \%$ for ever wheezing. The prevalence of respiratory medication and of doctors' diagnosis of asthma was higher in the study population as well. No differences were reported for frequency of earache, contacts with the family doctor, and absenteeism from school.

Table 2 also shows the results of the logistic regression analyses of chronic respiratory symptoms and allergy of the children. The results were adjusted for the potential confounding variables age, sex, education of the mother, passive smoking, presence of an unvented gas fired water heater, type of heating appliance, home dampness, presence of pet animals, and crowding (number of household members divided by number of rooms in the house). No other variables seemed to cause a significant change in the adjusted OR when added to the model.

The crude ORs differed only slightly from the adjusted ORs, so it can be concluded that little joint confounding was present. When examining models with one or more confounding variables separately, it seemed that only home dampness caused significant confounding. Indeed, in the control population significantly more houses were reported as damp, and respiratory symptoms of study sub- jects seemed to be related to home dampness. However, the separate confounding effect of home dampness seemed to be balanced by the effect of all the other covariates combined (data not shown).

Of nine adjusted ORs of chronic respiratory conditions (allergy not included) seven were greater than unity, ranging from 1.5 to $4 \cdot 8$. One of these, respiratory medication, was significant. One, ever wheezing, reached borderline significance $(P=0.05)$. Symptoms of wheeze, attacks of shortness of breath with wheeze, and medication had consistently high ORs, in contrast with complaints of dyspnoea.

For each respiratory condition, the number of subjects available for logistic regression was 41 to 43 lower than the number of subjects about which the outcome was known (columns 2 and 5 of table 2). This was due to questionnaires not fully completed (item nonresponse), mainly for questions about covariates. The phenomenon seems to have been selective: in the group of non-responders parents with children with respiratory symptoms were relatively overrepresented in the study population, and parents with healthy children in the control population (data not shown). As a consequence, crude ORs calculated for children with complete questionnaires were consistently lower than the crude ORs obtained from all children.

When we looked at boys and girls separately, in both groups prevalences of chronic respiratory conditions were larger in the study population. The difference between study and control populations was clearly larger for girls, with high and highly significant adjusted ORs for this sex group (table 3 ).

When studying the possibility of modification of effect by age, the results seemed to depend strongly on the choice of age categories. Stratified for age with the data divided into tertiles of age, the highest significant ORs were in the age group of 6-10 years, and in the age group $0-5$ years the ORs were consistently higher than 1 as well. In the age group of 11-15 years numbers were small causing numerical instability with unreliable results. ${ }^{14}$ When combining the categories of the 6-10 year olds with the 11-15 year olds, adjusted ORs for age 6-15 were about the same as those for age $0-5$. When splitting the data into two equal age groups (0-7 and 8-15), adjusted

Table 4 Logistic regression: numbers, crude ORs, adjusted ORs, and 95\% CIs of adjusted ORs for adults

\begin{tabular}{|c|c|c|c|c|}
\hline Symptom or item & Subjects ${ }^{\star} n$ & Crude OR† & Adjusted $O R$ & $(95 \% C I)$ \\
\hline Chronic cough-in past 2 years & 1108 & 0.9 & 0.9 & $0 \cdot 5-1 \cdot 4$ \\
\hline Chronic cough with phlegm - in past 2 years & 1103 & 0.9 & 0.8 & $0 \cdot 5-1 \cdot 4$ \\
\hline Wheeze - ever & 1113 & $1 \cdot 1$ & $1 \cdot 1$ & $0 \cdot 8-1 \cdot 3$ \\
\hline Wheeze lasting $>1$ week-occasionally in & & & & \\
\hline past 2 years & 1108 & $1 \cdot 1$ & $1 \cdot 1$ & $0 \cdot 6-1 \cdot 8$ \\
\hline Dyspnoea - occasionally (during walking) & 955 & $1 \cdot 7$ & 1.8 & $1 \cdot 1-3 \cdot 0$ \\
\hline Doctor's diagnosis of asthma - ever & 1110 & $1 \cdot 1$ & $1 \cdot 2$ & $0.8-1.9$ \\
\hline Respiratory medication - occasionally & 1117 & 0.9 & 1.0 & $0.6-1.5$ \\
\hline Chronic obstructive pulmonary disease & & & & \\
\hline medication-occasionally & 1105 & $1 \cdot 0$ & $1 \cdot 0$ & $0 \cdot 5-2 \cdot 0$ \\
\hline Asthma medication - currently & 1094 & $1 \cdot 1$ & $1 \cdot 2$ & $0 \cdot 4-3 \cdot 2$ \\
\hline Allergy - doctor's diagnosis ever & 1110 & $1 \cdot 0$ & $1 \cdot 1$ & $0.7-1.6$ \\
\hline
\end{tabular}

Allergy-doctor's diagnosis ever

1110

$1 \cdot 0$

Logistic regression with simultaneous adjustment for age, sex, education, smoking, presence of an unvented geyser, presence of a gas cooker, home humidity, presence of pet animals, crowding, and, when relevant, exposure to possible harmful air pollution at work. As to dyspnoea, adjustment for heart disease was included as well.

work. As to dyspnoea, adjustment for heart disease was included as well.
$\star$ Numbers of adults with complete data as used for calculation of adjusted ORs.

†Crude ORs calculated over the same number of cases as adjusted ORs. 
ORs were higher in the younger age group (data not shown).

Apart from sex and age, no other variable showed a significantly modifying effect, including duration of living at the present address.

ADULTS

Questionnaires were obtained from 1485 adults, an overall response of $63 \%$. In the study population the response rate was slightly lower than in the controls, $60 \%$ compared to $65 \%(P<0.05)$. There were no major inequalities in distributions of population characteristics.

Mean reported prevalences for chronic respiratory symptoms ranged from $6.0 \%$ for occasionally more than one week wheezing to $16.7 \%$ for occasional wheeze. The symptom dyspnoea during walking (mild shortness of breath) showed a higher prevalence in the study population, $13.3 \%$, compared with $10.3 \%$ in the controls $(P=0.08)$, but no other significant differences in prevalences between study and control populations were present. Table 4 shows the adjusted ORs of chronic respiratory symptoms. The table shows that the number of subjects with completed questionnaires was considerably lower than the total number of responders. Mild shortness of breath showed a significant adjusted OR of 1.8 controlling for potentially confounding variables including heart disease.

No modification of effect by age, sex, or duration of living could be found.

\section{Discussion}

The results of our study show higher prevalences for most respiratory conditions of children, as reported by parents who live along busy traffic roads compared with a suitable control population. The difference was still present when adjusted for confounding variables, but then was only significant for respiratory medication, and of borderline significance for ever wheezing with $P=0 \cdot 05$. Differences were more clear in girls than in boys. In adults, only dyspnoea was reported significantly more frequently by people living along busy traffic roads.

In children only two out of 12 respiratory conditions reached significance in multivariate analysis. However, given that seven out of nine respiratory conditions were above unity with a range from 1.5 to 4.8 , and considering the related $95 \%$ CIs as well, a certain consistency of the results seems to be present. Therefore, we consider these results to be suggestive of an association.

In adults only one symptom, dyspnoea, was significant. However, none of the other investigated respiratory conditions showed a clear departure from unity, and therefore we do not consider the overall results of adults as indicating a clear association with respiratory conditions.

Several remarks have to be made about the validity of our study. The response for children of $68 \%$ and for adults of $63 \%$ is more or less satisfactory. There were no indications for a selective non-response from the demographic data of the non-responders.

It may be that parents with children with respiratory symptoms prefer not to live along busy traffic streets. Some indication of such an effect is shown by the shorter mean duration of living at the present address of parents with children with symptoms of respiratory disease in the study population. The effect of such a selective migration would lead to underestimation of the risk of living on a busy road. The exposure and control population were highly comparable for sociodemographic variables, so no other mechanism of selective migration seems to have been operating.

Parents living in houses near busy traffic streets may be concerned, consciously or unconsciously, about the supposed detrimental influences of air pollution from the street on their children's health. In that case they may discern otherwise unnoticed airway symptoms of their children and report these in the questionnaire. Such an information bias (exposure suspicion bias) may have explained part of the results. The lack of increased prevalences of contact with the family doctor and of absenteeism from school points to this possibility.

On the other hand, the increased prevalence of use of respiratory medication and the tendencies towards increased prevalences of specific medication for asthma and of a doctor's diagnosis of asthma do not suggest information bias. These findings in turn may partly have been caused by diagnostic bias, but this supposes an awareness in family doctors of the exact living conditions of their patients that may not be warranted. To what extent exposure suspicion bias was actually present cannot be estimated precisely on the basis of our results.

Most demographic and housing variables were equally distributed among study and control populations, with home dampness as the only exception. Indeed, little confounding was present in the data, as is shown by the small difference between crude and adjusted ORs.

In the Netherlands, motorised traffic nowadays is the main source of several types of urban air pollution. ${ }^{18}$ However, at the time of this study, no direct information about actual levels of air pollution or contrasts in air pollution was available for the study area.

In recent years several studies have been published that reported differences in respiratory health indicators within cities, supposedly related to differences in traffic density and traffic related air pollution. Traffic related differences between neighbourhoods have been studied by Wjst et al ${ }^{19}$ and by Edwards et al. ${ }^{4}$ On a smaller geographical scale, air pollution levels may be high both in and close to streets with a high traffic density, with potential effects on respiratory health of residents living there. This hypothesis has been studied by Nitta et $a l,{ }^{5}$ Weiland $e t ~ a l,{ }^{3}$ and Edwards et $a l,{ }^{4}$ and has been the subject of our study as well. Table 5 shows the design and results of these four studies. 
Table 5 Summary of published studies on respiratory health of residents related to traffic in the street

\begin{tabular}{|c|c|c|c|c|}
\hline $\begin{array}{l}\text { Author and year } \\
\text { of publication }\end{array}$ & $\begin{array}{l}\text { Study design and } \\
\text { study population }\end{array}$ & $\begin{array}{l}\text { Exposure definition } \\
\text { and type of contrast }\end{array}$ & $\begin{array}{l}\text { Measurement } \\
\text { of health }\end{array}$ & Results: ORs (95\%CI) \\
\hline Nitta et al $1993^{5}$ & $\begin{array}{l}\text { Cross sectional } \\
\text { studies } 1979,1982, \\
1983 \text {. } \\
\text { Adult women of } \\
\geqslant 40 \mathrm{y}\end{array}$ & $\begin{array}{l}\text { Distance of living address } \\
\text { from major traffic arteries. } \\
\text { Comparison within neighbourhoods. }\end{array}$ & $\begin{array}{l}\text { Self reported respiratory } \\
\text { symptoms. }\end{array}$ & $\begin{array}{l}\text { Chronic cough, chronic phlegm, chronic } \\
\text { wheeze, shortness of breath, chest cold with } \\
\text { phlegm: Of } 20 \text { ORs } 17 \text { were above } 1 \text {, of } \\
\text { which } 8 \text { had } P<0.05 \text {. Highest was } \\
\text { chronic wheeze in } 1979 \text { with OR } 2 \cdot 8 \\
(1 \cdot 7-4 \cdot 7) \text {. }\end{array}$ \\
\hline Weiland et al 1994 3 & $\begin{array}{l}\text { Cross sectional study. } \\
\text { School children } \\
13-15 \text { y }\end{array}$ & $\begin{array}{l}\text { Traffic road as self defined by } \\
\text { the children. } \\
\text { Comparison of traffic roads with other } \\
\text { roads in the region: control streets } \\
\text { not paired with exposed streets. }\end{array}$ & $\begin{array}{l}\text { Self reported symptoms } \\
\text { of wheeze, including video } \\
\text { questionnaire. }\end{array}$ & $\begin{array}{l}\text { Wheeze: OR } 1.5(1 \cdot 1-2 \cdot 2), 1 \cdot 7(1 \cdot 1-2 \cdot 7) \text {, } \\
1.6(1 \cdot 1-2 \cdot 2), 1 \cdot 9(1 \cdot 3-3 \cdot 0) \text { for frequent or } \\
\text { constant lorry traffic, respectively with } \\
\text { written or with video questionnaire. }\end{array}$ \\
\hline Edwards et al 19944 & $\begin{array}{l}\text { Case control study, with } \\
\text { both hospital and } \\
\text { community controls. } \\
\text { Children } 0-4 \text { y }\end{array}$ & $\begin{array}{l}\text { Town district classified by number } \\
\text { of vehicles a day in major road in } \\
\text { district; distance from this major road. } \\
\text { Comparisons both between and within } \\
\text { neighbourhoods. }\end{array}$ & $\begin{array}{l}\text { Hospital admissions for } \\
\text { asthma. }\end{array}$ & $\begin{array}{l}\text { ORs within neighbourhoods: } 1.5(1 \cdot 2-1 \cdot 9) \text {, } \\
1 \cdot 2(0 \cdot 9-1 \cdot 4), \text { between neighbourhoods: } \\
1.4(1 \cdot 1-1 \cdot 7), 1 \cdot 3(1 \cdot 0-1 \cdot 5) \text {, for community } \\
\text { and hospital controls respectively. }\end{array}$ \\
\hline Wjst et al $1993^{19}$ & $\begin{array}{l}\text { Cross sectional study. } \\
\text { School children 9-11 y }\end{array}$ & $\begin{array}{l}\text { School district classified according to } \\
\text { highest traffic volume of main street. } \\
\text { Comparison between neighbourhoods. }\end{array}$ & $\begin{array}{l}\text { Respiratory symptoms as } \\
\text { reported by parents, and } \\
\text { pulmonary function. }\end{array}$ & $\begin{array}{l}\text { Of } 10 \text { reported respiratory symptoms } 8 \\
\text { were above } 1 \text { of which } 4 \text { had } P<0.05 \text {, } \\
\text { lifetime prevalence recurrent wheeze } 8 \% \\
\text { increase with each } 25000 \text { vehicles. Of } \\
8 \text { pulmonary function effects, } 4 \text { had } \\
P<0.05 \text {. }\end{array}$ \\
\hline
\end{tabular}

Nitta and coauthors described the results of three successive cross sectional surveys in the urban area of Tokyo, Japan, in which the people living within $20 \mathrm{~m}$ from major traffic arteries were compared with people living between $20-50 \mathrm{~m}$ and between $50-150 \mathrm{~m}$ from the road. Study subjects were women of 40 years of age or more, who supposedly spent much of their time indoors. Most of the adjusted ORs for self reported respiratory symptoms were above one with several of them reaching significance, the highest OR being 2.75 for chronic wheeze. Although the authors themselves suggest otherwise, the findings in these Japanese studies seem rather consistent. ${ }^{5}$

In the cross sectional study of Weiland et al in Bochum, Germany, respiratory health of seventh and eighth grade school children (age 13-15 years) was assessed by a self administered questionnaire focussing on symptoms of wheeze and allergic rhinitis, and a video questionnaire about symptoms of wheeze). ${ }^{3}$ With the same questionnaire information was obtained about whether the children lived on a major road, about the amount of lorry traffic passing through the street, and about several potential confounding variables. Living on a main road seemed to be associated with wheeze (OR $=1 \cdot 28)$, living in a road with frequent or constant lorry traffic was associated with wheeze $(O R=1.53)$ and with allergic rhinitis $(O R=1.94) .^{3}$

In a case-control design, Edwards and coauthors in Birmingham, compared all children admitted to a hospital with a diagnosis of asthma up to the age of four years with a sample of hospital controls, who were children admitted to a hospital for other reasons than asthma, such as trauma and traffic accidents. A second control population consisted of a random sample from the community. Home addresses of children were classified into 18 geographical town districts, categorised for traffic density according to two criteria: traffic flow in vehicles each day in the major road in the town district, and distance from this major traffic road in meters. The ORs for hospital admissions for asthma ranged from 1.16 to 1.52 according to the various analyses. $A$ trend with increasing traffic flow was present. ${ }^{4}$

Wjst et al found that in Munich, Germany, the prevalence of respiratory symptoms increased and pulmonary function decreased in primary school children as traffic on the main road in the school district increased. In Munich almost all children go to the primary school which is closest to their home, so this association also reflects the place of residence of children. ${ }^{19}$

Compared with these four reported studies, ours is the only one in which adults and children were investigated simultaneously. In our study, the children's ORs of symptoms of wheeze were consistently higher than one, whereas in adults only dyspnoea showed a clearly increased OR. This difference may indicate a difference in susceptibility to ambient traffic related air pollution between adults and children. Also, it could be that a possible effect of living along a busy street cannot be detected as easily for adults as for children within the larger context of other exogenous influences on respiratory health, including smoking. In the study of Nitta et al, estimated ORs for adults were consistently above 1 , but in that study, traffic density was much higher than in our study.

Although in the studies of Wjst et al, Weiland et al, Edwards et al, and in our study somewhat different exposure and outcome measurements were used, all four studies consistently indicated that living on or near busy roads has a detrimental effect on the respiratory health of children .

When estimated separately, ORs were significantly higher for girls than boys. It is well kwown that boys tend to have a higher incidence and prevalence of asthma and of lower respiratory tract illness than girls, ${ }^{20-22}$ and differences between boys and girls in characteristics and natural history of those illnesses have been reported..$^{21} 24$ This suggests that boys are in general more susceptible to respiratory disease than girls. In our study therefore, in boys the effect of living along a busy street may have been more difficult to detect in the presence of other exogenous influences. Also, responses to some exogenous factors may be sex dependent, 
as has been found in a study on effects of passive smoking. ${ }^{25}$ Unknown differences between sexes in time activity patterns and related levels of exposure may have played a part as well.

We think that our data were not consistent enough to warrant any interpretation of a possible modification of effect by age.

Our study took place in a medium sized urban area with traffic flow in the selected streets not surpassing 30000 vehicles a day. This may indicate that effects of air pollution related to traffic are not restricted to highly urbanised regions. It should be pointed out, however, that all studies reviewed here lack information about actual (personal) exposure of study subjects, and apart from the study by Wjst et al no measurements of pulmonary function were included.

Several authors have suggested the possibility of confounding as an explanation of results. If differences in socioeconomic characteristics and living conditions between exposed and control populations are large, it will be difficult to adjust for confounding completely, with a risk of residual confounding. Neighbourhoods with much traffic may differ in the kind of population or living conditions from other neighbourhoods. This may be important when randomly selected controls have been used. However, in the study of Weiland et al with random controls, almost no confounding of the variables measured seemed to have been present. Within neighbourhoods, the socioeconomic characteristics of the relatively small number of people living close to or along a major road may differ from characteristics of subjects living elsewhere in the neighbourhood, for instance due to selective migration effects related to noise. In our study, we have tried to exclude this particular bias by matching for neighbourhood and type of house in the sampling procedure. Indeed, the results show that almost all demographic variables were the same for exposed and control populations and the actual amount of confounding within neighbourhoods seemed to be small.

In conclusion, our study indicates that in a medium sized town living along busy traffic streets was associated with an increased prevalence of chronic respiratory symptoms, and of use of respiratory medication among children aged $0-15$. Adults living along busy streets reported only dyspnoea more often than adults in the less exposed control population.

This study was supported by a grant from the Ministry of Health (The Netherlands). We thank Antje Kleef and Peter Onel for their help during the study, and Resi Cluitmans, Erik Miltenburg, Mark van Bruggen, and Rik van de Weerdt for their useful comments.
1 Ware JH, Ferris BG Jr, Dockery DW, Spengler JD, Stram DO, Speizer FE. Effects of ambient sulfur oxides and suspended particles on respiratory health of preadolescent children. Am Rev Respir Dis 1986;133:834-42.

2 Dockery DW, Speizer FE, Stram DO, Ware JH, Spengler JD, Ferris BG Jr. Effects of inhalable particles on respiratory health of children. Am Rev Respir Dis 1989;139: 587-94.

3 Weiland SK, Mundt KA, Rückmann A, Keil U. Selfreported wheezing and allergic rhinitis in children and traffic density on street of residence. Ann Epidemiol 1994; 4:243-7.

4 Edwards J, Walters S, Griffiths RK. Hospital admissions for asthma in preschool children: relationship to major roads in Birmingham, United Kingdom. Arch Environ Health 1994;49:223-7.

5 Nitta H, Sato T, Nakai S, Maeda K, Aoki S, Ono M. Respiratory health associated with exposure to automobile exhaust. I. Results of cross-sectional studies in 1979, bile exhaust. I. Results of cross-sectional studies in 197 and 1983. Arch Environ Health 1993;48:53-8.

6 Eerens HC, Sliggers CJ, Hout KD van den. The CARmodel: the Dutch method to determine city street air quality. Atmospheric Environment part B: Urban Atmosphere 1993;27:389-99.

7 Florey C du V, Leeder SR. Methods for cohort studies of chronic airflow limitation. Copenhagen: World Health Organisation, Regional Office for Europe 1982. (European Series No 12.)

8 Biersteker K, Van Dijk WH, Eissens JBMF, Van Geuns HA. Ervaringen met geneeskundig onderzoek op CARA bij. gemeentepersoneel te Rotterdam in 1970-71 bij gemeentepersoneel te Rotterdam in 1970-71
(Experience with chronic respiratory disease medical experience with chronic respiratory disease medical 1970-1). Tijdschr Soc Geneesk 1974;52:158-62.

9 Schlesselman JJ. Case-control studies. Design, conduct, analysis. New York/Oxford: Oxford University Press 1982;194

10 Dean AD, Dean JA, Burton AH, Dicker RC. Epi Info, version 5: a word processing, database, and statistics program for epidemiology on micro-computers. Stone Mountain, Georgia, USA: USD, 1990.

11 Kleinbaum DG, Kupper LL, Morgenstern H. Epidemiological research. Principles and quantitative methods. New
York: Van Nostrand Reinhold Company 1982; York: Van No

12 Greenland, S. Modeling and variable selection in epidemiological analysis. Am $\mathcal{F}$ Public Health 1989;79:340-9.

13 Mickey RM, Greenland S. The impact of confounder selection criteria on effect estimation. Am $\mathfrak{f}$ Epidemiol 1989;129:125-37.

14 Hosmer DW, Lemeshow S. Applied logistic regression. New York: John Wiley 1989;126-33.

15 Norusis MJ. SPSS/PC+ Advanced satistics for the IBM $P C / X T / A T$ and $P S / 2$. Chicago, Illinois: SPSS, 1990

16 Kalton G. Introduction to survey sampling. Newburg Park, London, New Delhi: Sage 1983;28-38.

17 Levy PS, Lemeshow S. Sampling for health professionals. Belmont, California: Lifetime Learning Publications 1980;220-1.

8 Eerens HC. Air pollution in towns. In: National Institute of Public Health and Environmental Protection. National environmental outlook 1990-2010. Bilthoven, The Netherlands: 1992

19 Wjst M, Reitmeir P, Dold S, Wulff A, Nicolai T, Von Loeffelholz-Colberg E, Von Mutius E. Road traffic and adverse effects on respiratory health in children. $B M \mathcal{F}$ adverse effects on

20 Anderson HR, Bland JM, Patel S, Peckham C. The natural history of asthma in childhood. $\mathcal{F}$ Epidemiol Community Health 1986;40:121-9.

21 Sherman CB, Tosteson TD, Tager IB, Speizer FE, Weiss ST. Early childhood predictors of asthma. Am $\mathcal{J}$ Epidemiol 1990;132:83-95.

22 Gold DR, Rotnitzky A, Damokosh AI, Ware JH, Speizer FE, Ferris BG, Dockery DW. Race and gender differences in respiratory illness prevalence and their relationship to environmental exposures in children 7 to 14 years of age. Am Rev Respir Dis 1993;148:10-8.

23 Strope GL, Stewart PW, Henderson FW, Ivins SS, Strope GL, Stewart PW, Henderson FW, Ivins SS,
Stedman HC, Henry MM. Lung function in school-age Stedman HC, Henry MM. Lung function in school-age
children who had mild lower respiratory illnesses in early children who had mild lower respiratory illnesses

24 Weiss ST, Tosteson TD, Segal MR, Tager IB, Redline S, Speizer FE. Effects of asthma on pulmonary function in children. A longitudinal population-based study. Am Rev Respir Dis 1992;145:58-64.

25 Sherrill DL, Martinez FD, Lebowitz MD, Holdaway MD, Flannery EM, Herbison GP, et al. Longitudinal effects of passive smoking on pulmonary function in New Zealand children. Am Rev Respir Dis 1992;145:1136-41. 